\title{
JAMAIS TORTARÃO AS GARRAS DAS FELINAS
}

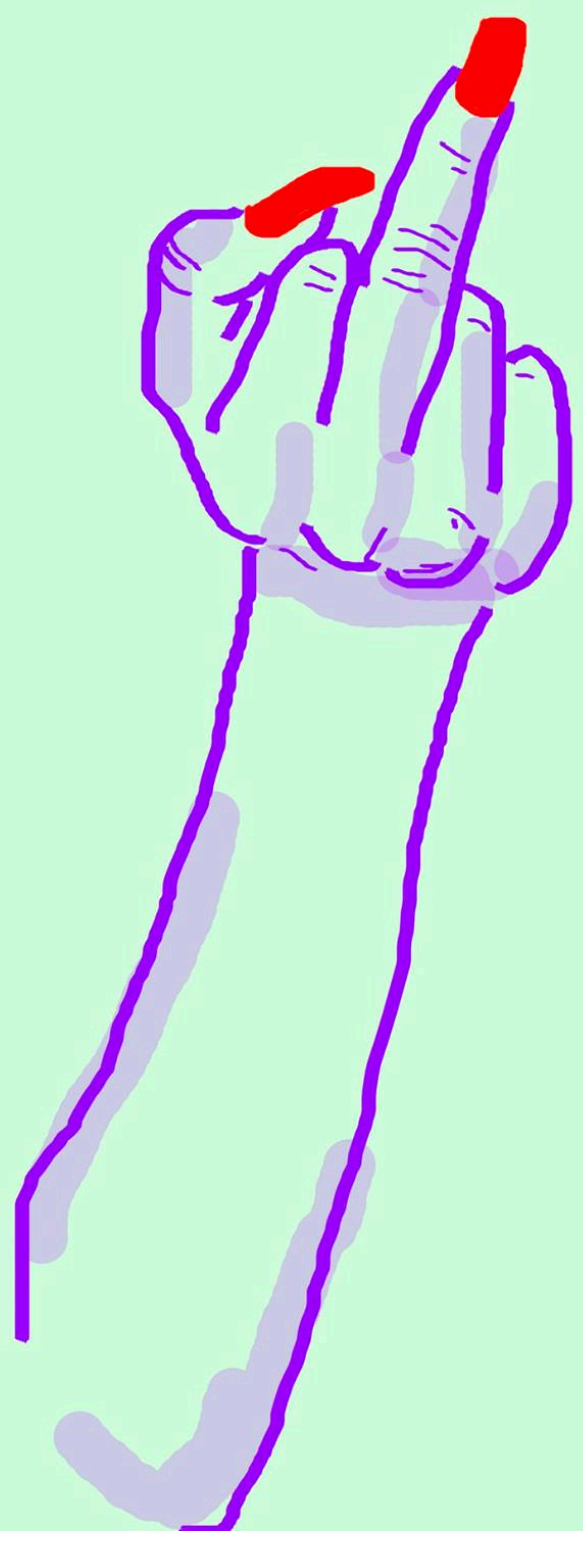




\section{JAMAIS toRTARÃO AS GARRAS DAS FELINAS}

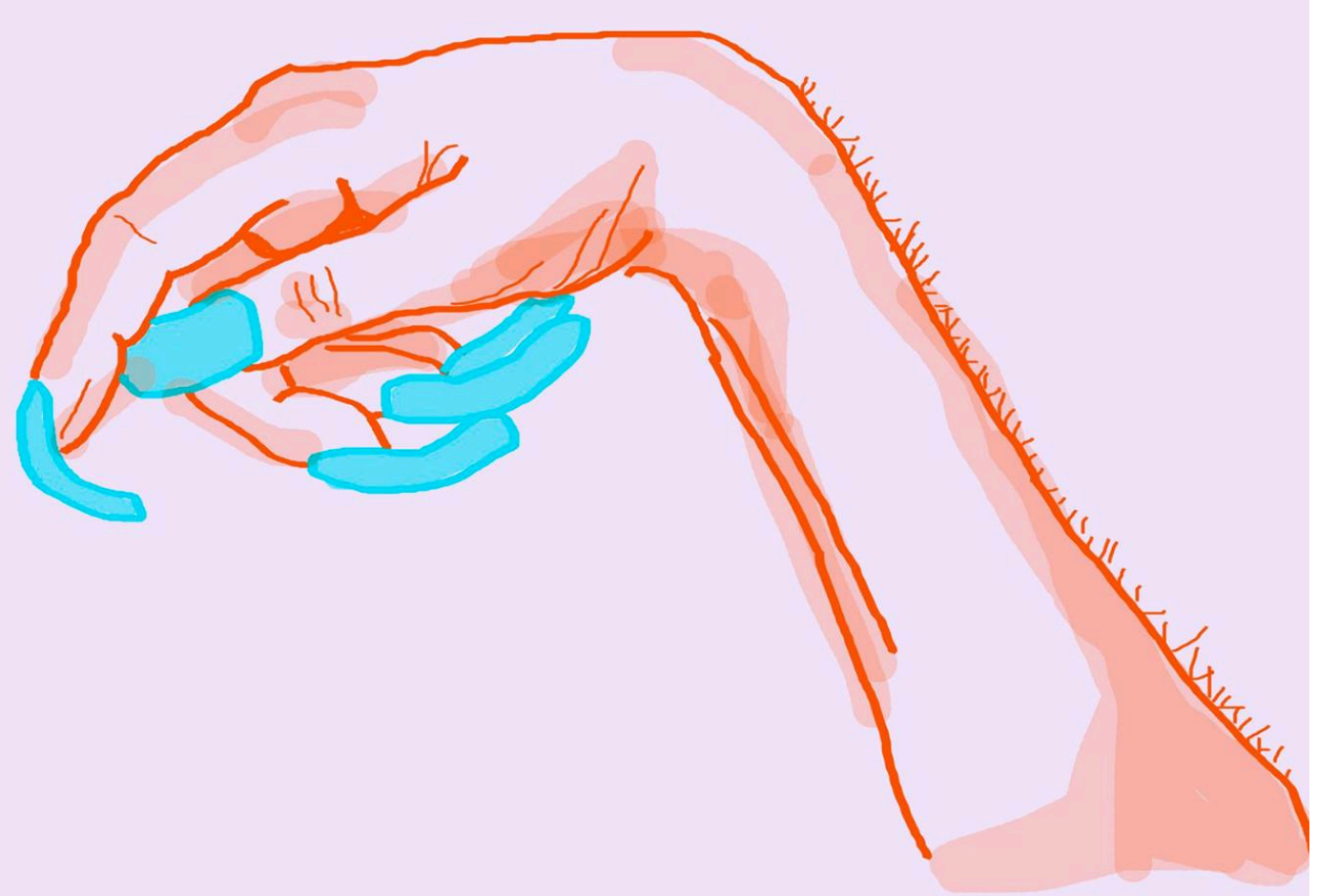




\section{JAMAIS TORTARÃO AS GARRAS DAS TELINAS}

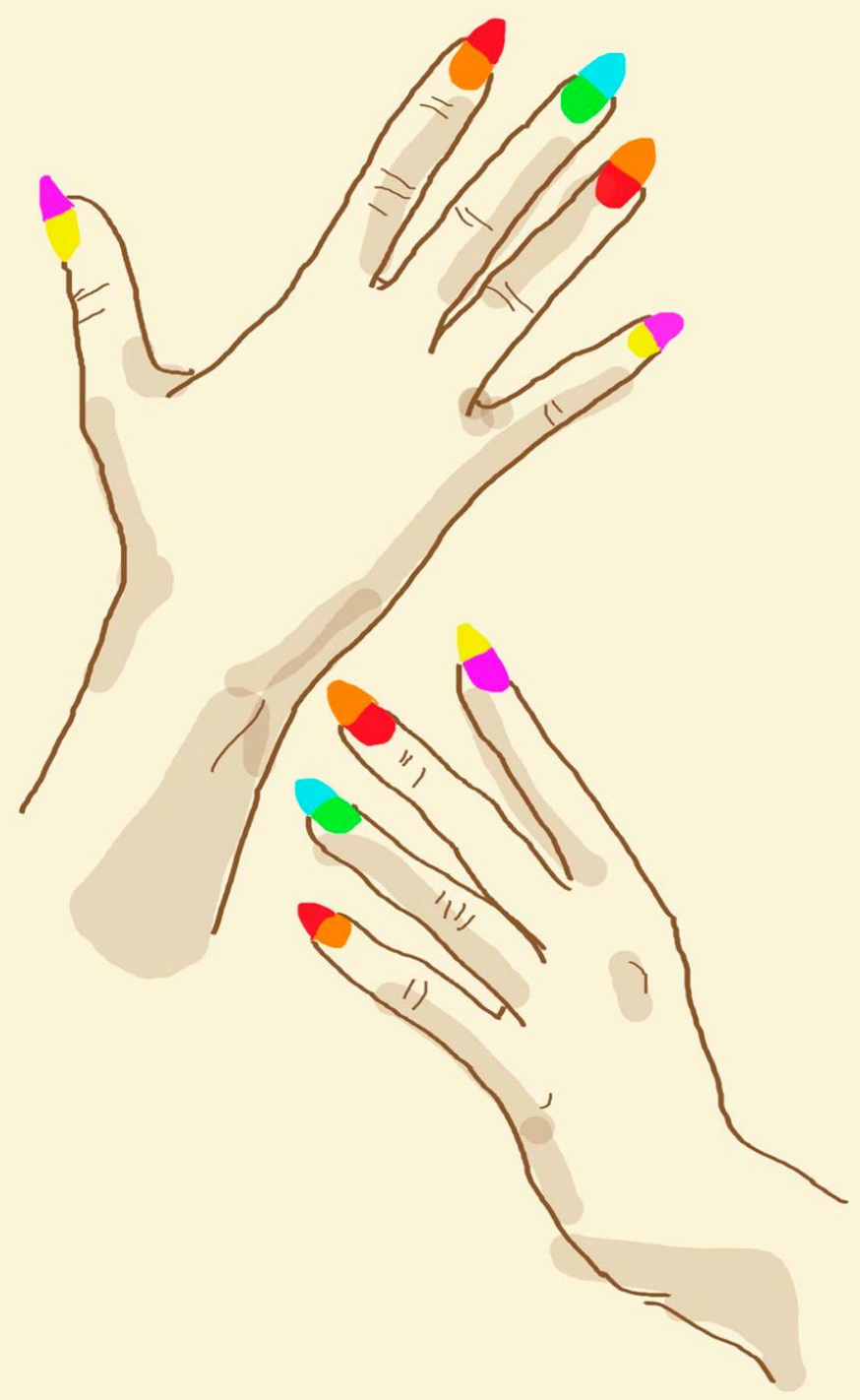




\section{JaMAIS TORTARÃO AS GARRAS DAS TELINAS}

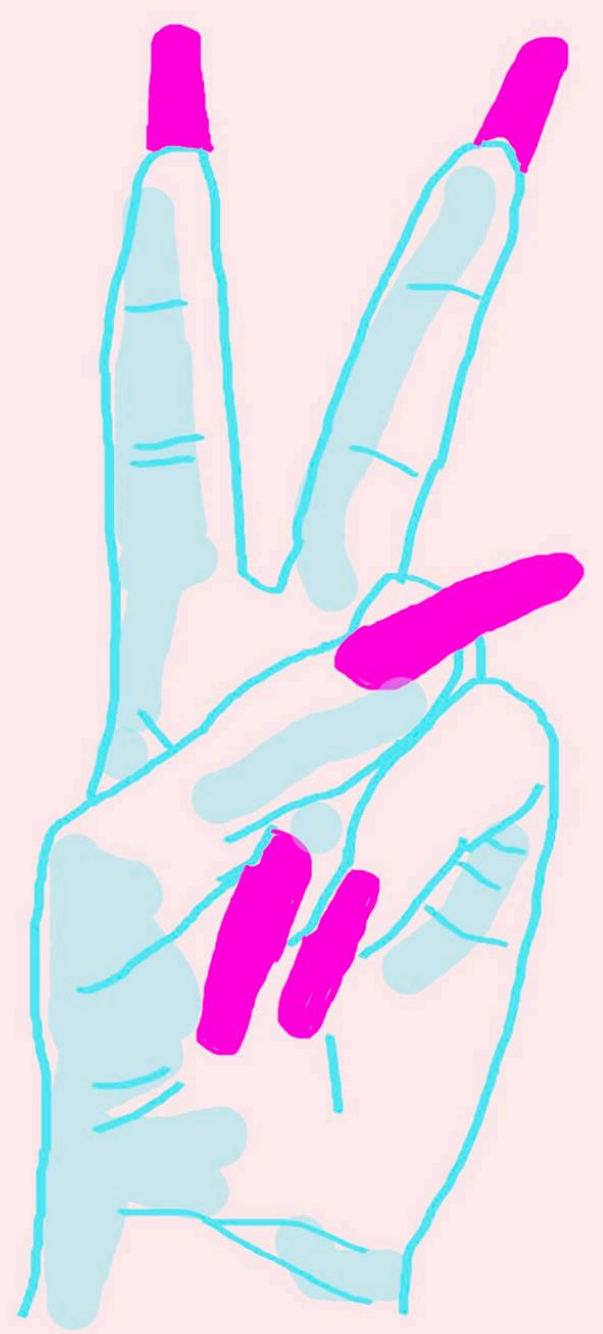

